\title{
Quantificação em escala de bancada do volume de ar em ligações prediais de água
}

\section{Measuring air volume in household pipes by means of a pilot scale study}

\author{
Ney Procópio Lopes \\ Engenheiro Civil da Prefeitura de Pouso Alegre (MG). Mestre em Saneamento, Meio Ambiente e Recursos Hídricos pela Universidade Federal de Minas Gerais (UFMG)

\section{Márcia Lara ${ }^{1}$} \\ Engenheira Civil e Mestre em Engenharia Sanitária pela UFMG. Doutora em Hidráulica pela Escola Politécnica da Universidade de São Paulo (USP). Pós- \\ doutorado pela Ecole Polytechnique Federale de Lausanne (Suíça). Pesquisadora da Fundação de Amparo à Pesquisa do Estado de Minas Gerais (FAPEMIG). \\ Professora Associada do Departamento de Engenharia Hidráulica e Recursos Hídricos da UFMG
}

\section{Marcelo Libânio}

Engenheiro Civil e Mestre em Engenharia Sanitária pela UFMG. Doutor em Hidráulica e Saneamento pela Escola de Engenharia de São Carlos da USP. Pósdoutorado pela Universidade de Alberta (Canadá). Pesquisador do Conselho Nacional de Desenvolvimento Científico e Tecnológico (CNPq) e da FAPEMIG.

Professor Associado do Departamento de Engenharia Hidráulica e Recursos Hídricos da UFMG

\section{Resumo}

A presente pesquisa em escala piloto, simulando trecho de uma rede interligada a um ramal predial, visou quantificar o volume de ar aferido pelos hidrômetros residenciais. Para tal fim, testaram-se ventosas, bloqueadores de ar e válvulas eliminadoras de ar. Sob condições normais de operação da rede, o volume de ar medido pelos hidrômetros é comparável ao encontrado na água natural, não justificando a instalação de equipamento de eliminação de ar de qualquer natureza. Todavia, logo após esvaziamento da rede interligada ao ramal, a sobremedição pode atingir até 21\% em condições de pressão máxima na rede de distribuição (500 kPa). Por fim, verificou-se que a menor vazão afluente associa-se ao maior volume de ar aferido pelo hidrômetro. Dessa forma, é possível supor que os consumidores situados na menor faixa de consumo sejam os mais prejudicados pela situação de desabastecimento.

Palavras-chave: presença de ar na água; eliminadores de ar; abastecimento de água.

\section{Abstract}

The purpose of the present work is to evaluate the volume of air measured in domestic water supply pipe connections. Tests were performed to evaluate the efficiency and applicability of air reducing valves in domestic water supply connections. The results obtained under regular water supply conditions showed that the volume of air in the water measured by the hydrometers is comparable to the one found in natural waters. On the other hand, other tests, right after emptying the network connected to the domestic water supply pipe, revealed that the volume of water which gets to the gauged reservoir comprehends up to $21 \%$ of the total air-water volume recorded by the hydrometer for the experiments performed under pressure of $500 \mathrm{kPa}$.

Keywords: water consumption; household water consumption; water supply system.

\section{Introdução e relevância}

A despeito do controle ao consumo exercido pelo hidrômetro, em diversos sistemas de abastecimento de água o aumento do consumo domiciliar - frequentemente relacionado ao aumento da renda per capita da população -, aliado à falta de investimento do prestador na ampliação e melhoria do sistema, tem provocado intermitência no fornecimento e admissão de ar nas tubulações. Embora a afluência de ar possa ocorrer de outras formas, surge, então, por parte da população abastecida a suspeita de que haveria ar sendo medido e cobrado em suas contas mensais de água. Devido à falta de uma norma que regulamente a fabricação e aplicação de equipamentos para redução de ar nas ligações prediais, há recusa sistemática por parte dos prestadores de serviços de abastecimento de água em instalar o equipamento, dando origem a uma série de ações judiciais de interesse dos consumidores que tramitam em diversas comarcas. 
Diversos setores e organizações da sociedade civil têm se interessado por equipamentos que eliminem o ar antes do hidrômetro. Um desses equipamentos, denominado eliminador de ar, surgiu em 1991, possuindo o mesmo princípio de funcionamento da ventosa simples. Algumas empresas que comercializam esse equipamento acenam com redução de até 35\% no valor mensal da conta de água. Outro tipo de equipamento, denominado bloqueador de ar, cuja instalação efetua-se após o hidrômetro, não havendo, assim, possibilidade de restrição da instalação dos mesmos pelo prestador. O princípio de funcionamento baseia-se, segundo o fabricante, na identificação do fluido por meio do diferencial de pressão ar-água. Entretanto, ainda não há registro de sua eficiência na literatura técnica.

Especificamente no estado de Minas Gerais, a Lei 12.645/97 torna obrigatória a instalação do equipamento eliminador de ar quando solicitado pelo consumidor. A regulamentação deu-se por meio de um Termo de Ajuste de Conduta celebrado em 2006 entre a Fundação Programa de Orientação e Proteção ao Consumidor (Procon) estadual, a Companhia de Saneamento de Minas Gerais (Copasa) e o Movimento das Donas de Casa e Consumidores de Minas Gerais, fixando prazos e preços para a instalação do equipamento.

\section{Presença de ar nas águas de consumo}

\section{Fatores intervenientes}

A afluência de ar nas tubulações de água pode advir de um ou mais fatores. Inicialmente, vale ressaltar que as águas naturais, nas temperaturas da ordem de $20^{\circ} \mathrm{C}$, contêm certa quantidade de ar dissolvido, cuja concentração de saturação - decorrente da pressão parcial deste gás - é de aproximadamente $2 \%$ em termos de volume. O ar normalmente dissolvido na água, de acordo com a lei de Henry, pode ser liberado caso haja diminuição da pressão e/ou aumento da temperatura da água durante o escoamento.

Entretanto, em outras situações, o ar pode ser introduzido nas tubulações (TSUTIYA, 2005):

- pelo preenchimento ou esvaziamento das adutoras e trechos da rede de distribuição;

- pelo baixo nível de água nos reservatórios, ocasionando vórtices na tubulação de saída;

- durante a formação do ressalto hidráulico em trechos da adutora em superfície livre;

- quando da utilização de águas naturais de qualidade inferior, pela formação de gás por meio da atividade biológica;

- em trechos das adutoras e redes de distribuição nos quais ocorrem pressão negativa;

- em menor monta, pelo processo de cavitação das bombas.

\section{Padrões de escoamentos ar/água em tubulações}

Segundo Falvey (1980), os diversos padrões de escoamentos possíveis no caso de escoamento conjunto de água e ar variam de acordo com a inclinação das tubulações. Os escoamentos verticais apresentam maior simetria em relação ao eixo da tubulação e manifestam-se de seis distintas formas, conforme denota a Figura 1.

Os padrões de escoamento em tubos inclinados manifestam-se da mesma forma que nos escoamentos verticais, exceto pela limitação ou total supressão do escoamento de bolhas.

A maioria dos escoamentos em tubos horizontais mostra padrão não simétrico devido aos efeitos da força da gravidade em fluidos de massas específicas distintas, caso do ar $\left(1,2 \mathrm{~kg} / \mathrm{m}^{3}\right.$ a $\left.0^{\circ} \mathrm{C}\right)$ e da água $\left(1000 \mathrm{~kg} / \mathrm{m}^{3}\right.$ a $\left.4^{\circ} \mathrm{C}\right)$. Isso gera tendência à estratificação na direção vertical, que significa que o escoamento do líquido tenderá a ocupar a parte mais baixa do tubo e forçar o ar ou vapor na direção da geratriz superior. Esses sete padrões são exemplificados pela Figura 2.

\section{Estudos de remoção de ar nas tubulações}

Principalmente a partir da década de 1940, pesquisas delinearam equações que estabelecem velocidade crítica mínima de escoamento para permitir a remoção e/ou o deslocamento dos bolsões de ar para os pontos mais elevados, a fim de que sejam eliminados pelas ventosas ou outros dispositivos. Little (2002) promoveu revisão detalhada de amplo conjunto de estudos experimentais acerca dos mecanismos do transporte de bolsões de ar em tubos e identificou algumas inconsistências entre os resultados publicados. A despeito de algumas limitações, foi possível concluir que o trabalho elaborado por Kent (1952 apud LITTLE, 2002) é o mais adequado para a determinação da velocidade crítica e:

a) que as bolhas de ar serão transportadas mais prontamente do que bolsões de ar, mas tenderão a aglomerar-se em bolsões de ar na parte superior da tubulação;

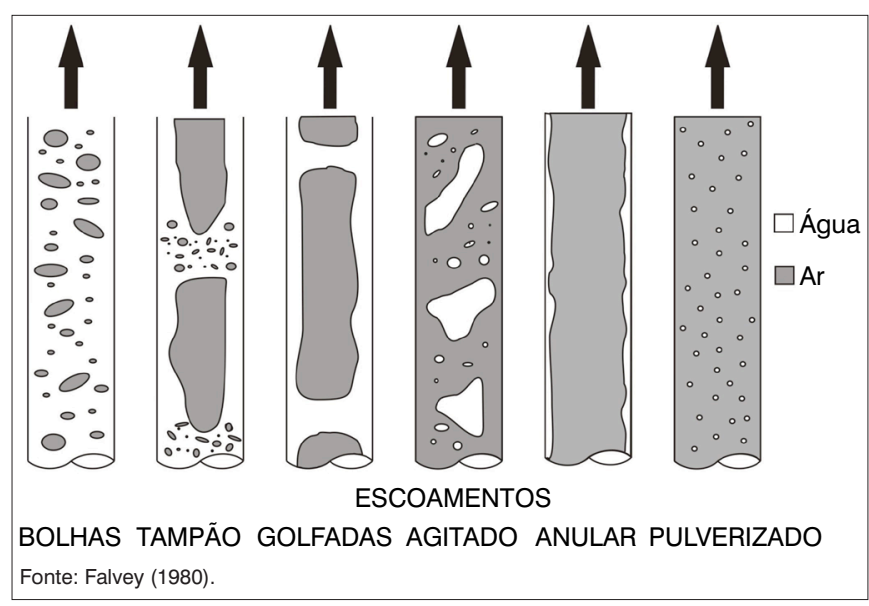

Figura 1 - Padrões de escoamento ar/água em tubulações verticais. 


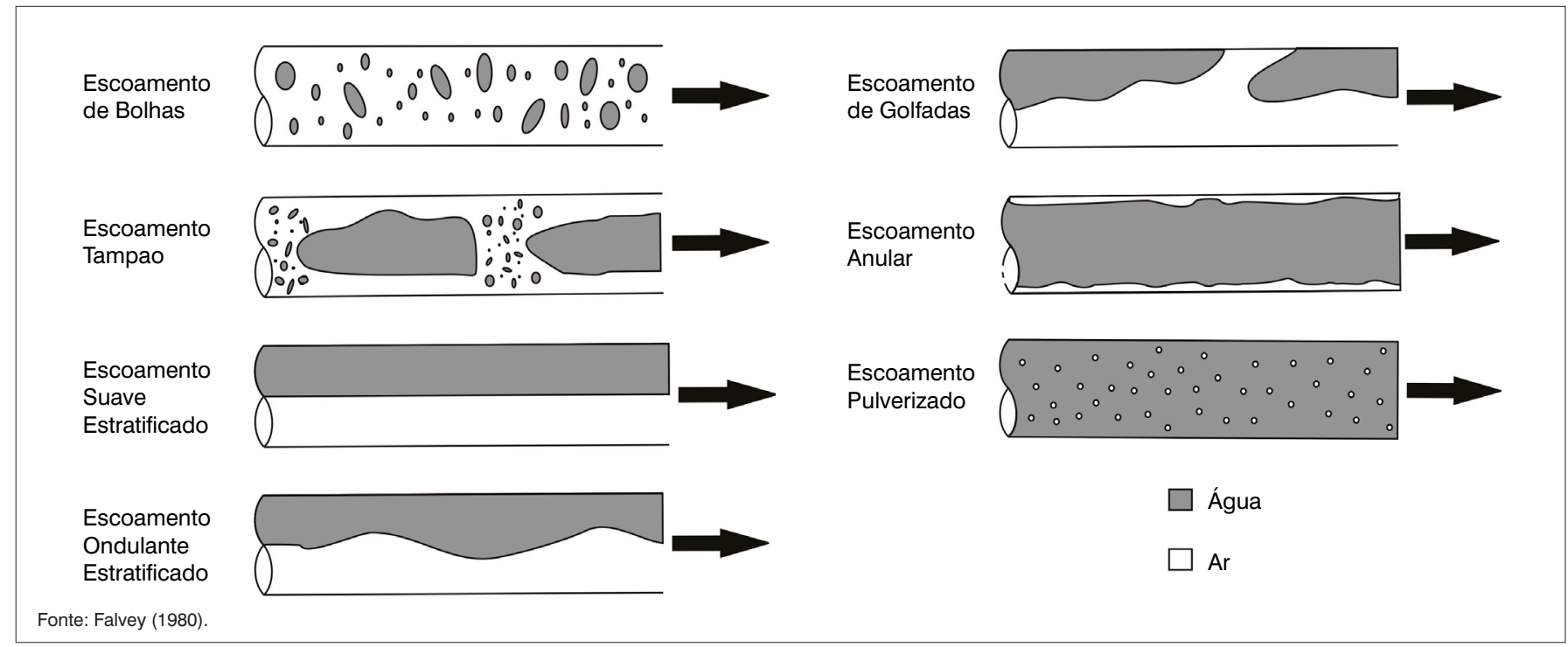

Figura 2 - Padrões de escoamento ar/água em tubulações horizontais.

b) que, sob típicas condições de operação, os bolsões de ar serão transportados a jusante em tubos com baixas inclinações, mas não serão transportados contra inclinações íngremes. Para um dado diâmetro e inclinação de tubo, existe uma taxa de escoamento crítica, na qual os bolsões de ar ficarão presos;

c) para tubulações inclinadas negativamente a jusante, Kent (1952 apud LITTLE, 2002) propôs a Equação 1 para cálculo da velocidade crítica $(\mathrm{Vc})$ em $\mathrm{m} / \mathrm{s}$, sendo $\mathrm{C}_{0}$ um adimensional obtido experimentalmente igual a 1,53, D o diâmetro do tubo em metro, $\theta$ o ângulo que a tubulação forma com a horizontal em graus e g a aceleração da gravidade $\mathrm{em} \mathrm{m} / \mathrm{s}^{2}$.

$V c / \sqrt{g D}=\sqrt{C_{0} \cdot \operatorname{sen} \boldsymbol{\theta}}$

Equação 1

No Brasil, só recentemente o assunto tem despertado a atenção dos técnicos devido à polêmica gerada em torno do volume de ar medido pelo hidrômetro. Como consequência, a maioria das pesquisas relacionadas foi encomendada pelos prestadores de serviços de abastecimento de água e relacionam-se aos mencionados equipamentos eliminadores de ar.

Mello e Farias (2001) submeteram dois tipos de eliminadores de diferentes fabricantes à avaliação na rede de distribuição operada pelo DMAE de Porto Alegre. Os testes foram conduzidos - com tempo mínimo de 12 meses - em áreas que apresentavam deficiência no abastecimento. A instalação dos eliminadores de ar deuse entre dois hidrômetros ligados em série, previamente aferidos. Ambos equipamentos apresentaram baixa eficiência e, em alguns casos, o valor registrado no segundo hidrômetro foi superior ao do primeiro hidrômetro. Constatou-se variação de consumo registrado no segundo hidrômetro em uma faixa de -8,3\% a +6,1\% em relação ao consumo no hidrômetro de montante. Adicionalmente, segundo os autores, verificou-se também possibilidade de contaminação da água distribuída.

Leal e Teixeira (2004) realizaram, na rede de distribuição de Juiz de Fora (MG), estudo com a finalidade de avaliar a eficácia do equipamento eliminador de ar em ligações prediais e a possibilidade de contaminação da água distribuída. Os testes de campo foram conduzidos por período de 11 meses e o aparato experimental foi instalado em 10 pontos que representassem a diversidade operacional da rede - em termos de pressão e perenidade do abastecimento. A montante do cavalete do usuário, instalou-se o equipamento de eliminação de ar entre dois outros hidrômetros idênticos, instalados em série. Os resultados demonstraram que os equipamentos eliminadores de ar não apresentam eficiência que justifique sua instalação e que $91 \%$ dos equipamentos testados apresentaram possibilidade de contaminação da rede.

Com aparatos experimentais semelhantes, resultados idênticos foram obtidos em estudos realizados pela Copasa em 2004, e pela Companhia de Água e Esgoto do Distrito Federal (Caesb) em 2005.

\section{Dispositivos de remoção de ar das tubulações}

No início do século XX, ainda não se compreendia bem o comportamento do ar dentro dos condutos. Optava-se pela instalação de piezômetros - cuja conexão com o conduto dava-se por meio de válvula manual, acreditando que grandes volumes de ar poderiam ser por eles expulsas para atmosfera. Rapidamente, constatou-se que essa solução somente poderia ser utilizada em pontos de baixa pressão.

Outra solução recaiu para os hidrantes de prevenção a incêndio instalados nas adutoras e redes de distribuição. Tratava-se 
de uma solução de baixa eficiência, uma vez que uma parcela significativa de ar acumula-se nos pontos altos das redes de distribuição e adutoras, onde comumente os hidrantes não eram instalados. Terceira alternativa consistia de uma válvula globo ou de gaveta instalada nos pontos altos que, operadas manualmente, expulsariam o ar. Em grandes sistemas, é impossível prever quando essas válvulas deverão ser abertas para expulsar o ar, além de não dotar os sistemas de proteção eficiente quando da ocorrência de vácuo e nem permitir a contínua expulsão do ar durante a operação.

As válvulas de ar, comumente denominadas ventosas, constituem os dispositivos mais comumente utilizados para eliminar o ar admitido durante as operações de enchimento ou esvaziamento das tubulações. O mau funcionamento das válvulas de ar pode ocasionar o acúmulo de ar em pontos onde nos quais as mesmas não funcionam adequadamente. Atualmente, grande número de válvulas de ar é utilizado em todo o mundo. A operação dessas válvulas é automática, admitindo ou expulsando ar sem a necessidade de interferência externa.

Diante do exposto, o presente estudo objetiva, além de avaliar a eficiência desses equipamentos na retirada do ar, verificar as diversas situações em que ocorre a admissão de ar nas redes de distribuição. A motivação do estudo fundamenta-se no fato da maioria das pesquisas de campo citadas não poderem realizar adequado controle das variáveis do fenômeno. Por outro lado, as experiências de laboratório, embora tivessem as variáveis mais bem controladas, não adotaram a mesma metodologia, pois ainda não há nas normas brasileiras procedimentos para os ensaios dos equipamentos envolvidos. Mesmo as ventosas, há muito utilizadas nas tubulações, não dispõem de procedimentos que regulamentem os testes efetuados.

\section{Objetivos}

\section{Geral}

Avaliar em escala piloto, em condições de funcionamento normal e de desabastecimento, a quantidade de ar em uma ligação predial medida por hidrômetros velocimétricos.

\section{Específicos}

Adicionalmente o estudo também visa à:

i) quantificação do volume de ar medido em uma ligação predial de água em função da pressão na rede de abastecimento;

ii) avaliação da eficiência de dois tipos de equipamentos destinados à remoção de ar nos ramais prediais;

iii) avaliação da eficiência das ventosas na remoção de ar instalada em um ponto alto da rede de abastecimento.

\section{Metodologia}

\section{Aparato experimental}

O aparato compôs-se de uma tubulação de comprimento $50 \mathrm{~m}$ e diâmetro 100 mm, que simula uma rede de abastecimento, possuindo uma inclinação ascendente de 1\% no sentido do escoamento. A tubulação interligou-se a um sistema de bombeamento por um lado e, por outro, aos ramais prediais de diâmetros de $15 \mathrm{~mm}(1 / 2 "), 20 \mathrm{~mm}\left(3 / 4^{\prime \prime}\right)$ e $25 \mathrm{~mm}$ (1"). Em cada um desses ramais instalaram-se, em série, dois hidrômetros velocimétricos, a montante e a jusante do equipamento de eliminação de ar a ser testado.

Na Figura 3A, apresentam-se o conjunto moto-bomba com suas tubulações de sucção e recalque, o reservatório principal de $1.300 \mathrm{~L}$, a rede de abastecimento e sua tubulação de descarga. Na Figura 3B, mostram-se o reservatório de calibração (com 255 $\mathrm{mm}$ de diâmetro, 2,0 $\mathrm{m}$ de altura e volume $102 \mathrm{~L}$ ) e a bomba auxiliar. Na Figura 3C, destacam-se os três ramais prediais interligados a montante pela rede de abastecimento, e a jusante aos cavaletes, sendo o primeiro para a instalação da válvula redutora de ar imediatamente após a válvula de retenção, e o segundo cavalete destinado à estrutura de medição. A válvula de retenção tem sido uma das exigências da prestadora para a instalação dos equipamentos redutores de ar.

A água proveniente da rede de distribuição abastecia os ramais prediais, sendo conduzida ao reservatório calibrado, utilizado para aferir o volume de água ou retornar ao reservatório principal. O conjunto moto-bomba principal, da marca Mark Peerless, possuía capacidade para aduzir $5 \mathrm{~m}^{3} / \mathrm{h}$ e altura manométrica total de 60 mca. O conjunto auxiliar tinha função de esvaziar o recipiente calibrado e a rede de distribuição. Para permitir as várias vazões e pressões necessárias aos testes, o conjunto moto-bomba principal foi interligado a um variador de frequência Siemens CFW 9.

Utilizaram-se hidrômetros da marca LAO, magnéticos, Classe $C$, vazão nominal de $2,5 \mathrm{~m}^{3} / \mathrm{h}$, vazão máxima de $5,0 \mathrm{~m}^{3} / \mathrm{h}$ e mínima de $0,05 \mathrm{~m}^{3} / \mathrm{h}$, previamente aferidos. A opção por hidrômetros de maior capacidade $\left(5 \mathrm{~m}^{3} / \mathrm{h}\right)$, em detrimento do hidrômetro $3 \mathrm{~m}^{3} / \mathrm{h}$ (vazão máxima $3,0 \mathrm{~m}^{3} / \mathrm{h}$ e mínima de $0,03 \mathrm{~m}^{3} / \mathrm{h}$ ), comumente utilizados em ramais de $20 \mathrm{~mm}$, deveu-se ao fato de que as vazões estabelecidas para os ensaios (vazão mínima de $0,18 \mathrm{~m}^{3} / \mathrm{h}$ e máxima de $1,5 \mathrm{~m}^{3} / \mathrm{h}$ ) poderiam ocasionar erros de medição além dos esperados para o limite superior das vazões de teste. Segundo a Norma Brasileira NBR NM 212/99, para vazões compreendidas entre a vazão máxima e 5\% desta, os erros esperados nas medidas realizadas pelos hidrômetros taquimétricos são da ordem de $2 \%$ e para as vazões inferiores a 5\% da vazão máxima o erro esperado é da ordem de $5 \%$. Testes complementares, com medida de volume 


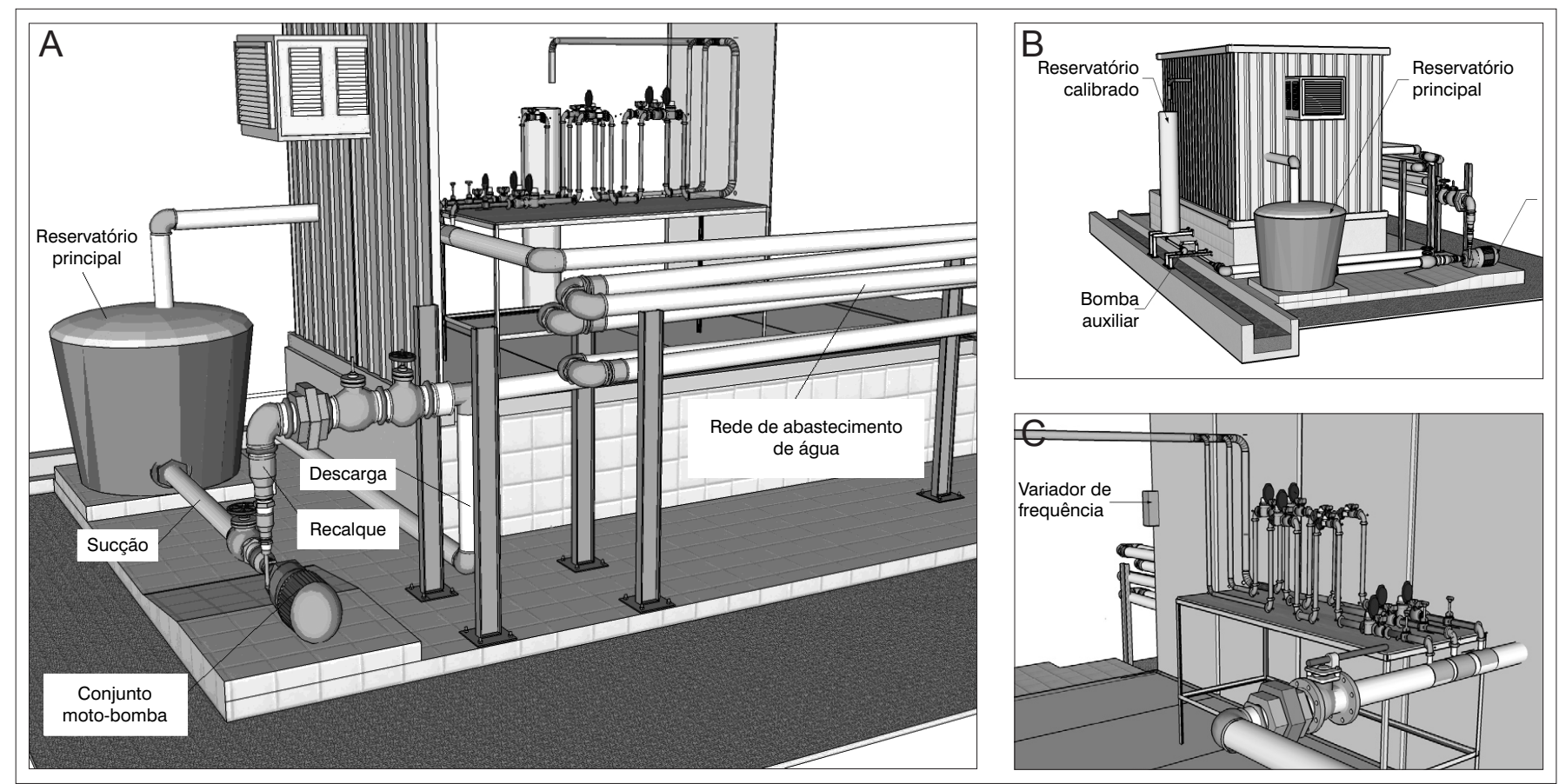

Figura 3 - Vista do aparato experimental.

fornecida pelo hidrômetro, efetuada no ramal de $20 \mathrm{~mm}$ e aferida no reservatório de calibração da Figura 3B, apresentaram coeficientes de determinação próximo à unidade. Os testes de aferição dos hidrômetros confirmaram erros da mesma ordem de grandeza dos estipulados pela NBR NM 212/99, ou seja, para as vazões estabelecidas nos ensaios e para os hidrômetros de $5 \mathrm{~m}^{3} / \mathrm{h}$ o erro foi da ordem de $2 \%$ para as vazões superiores a $0,25 \mathrm{~m}^{3} / \mathrm{h}$ e entre $2 \mathrm{e}$ $5 \%$ para as vazões de teste de $0,18 \mathrm{~m}^{3} / \mathrm{h}$.

As pressões foram aferidas por meio de manômetros do tipo Bourdon, com escala compreendida entre 0 e $10 \mathrm{kgf} / \mathrm{cm}^{2}$, e faixa de leitura de $0,1 \mathrm{kgf} / \mathrm{cm}^{2}$.

\section{Protocolo dos ensaios}

Os ensaios foram realizados com dois equipamentos distintos de um mesmo fabricante, exceto a ventosa simples com uma única unidade. O protocolo experimental visou reproduzir a faixa de vazão de trabalho dos hidrômetros normalmente utilizados nos ramais prediais e as pressões mínima e máxima da rede de distribuição admitidas pela NBR 12211 (100 e 500 kPa). O fluxograma dos ensaios apresenta-se na Figura 4.

A faixa de vazões foi estabelecida para os hidrômetros instalados em ramais prediais de $20 \mathrm{~mm}$ segundo a Portaria Inmetro 246/2000 e a NBR 12218. Os ensaios foram realizados próximos aos limites inferior e superior de trabalho dos hidrômetros, quais sejam, as vazões de $0,18 \mathrm{~m}^{3} / \mathrm{h}$ e $0,75 \mathrm{~m}^{3} / \mathrm{h}$, condições hidráulicas normais de trabalho dos hidrômetros instalados em ligações

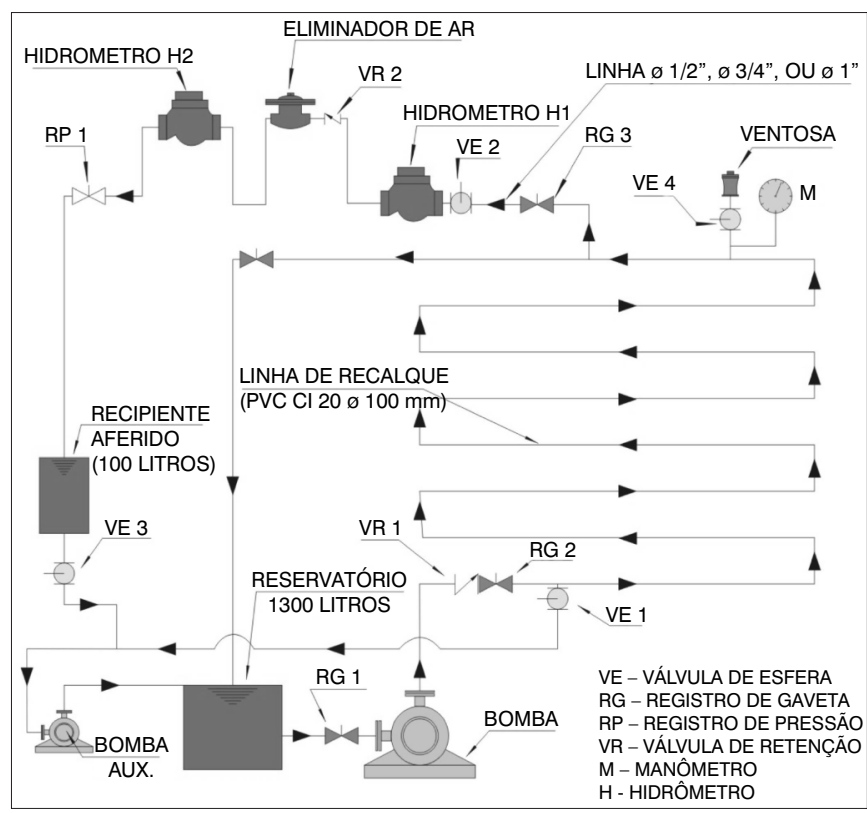

Figura 4 - Fluxograma dos ensaios experimentais.

prediais. Foram acrescentadas mais duas vazões: $1,50 \mathrm{~m}^{3} / \mathrm{h}$, vazão nominal do hidrômetro predial, e 1,00 m³/h, como vazão intermediária em faixa imediatamente acima ao limite superior da faixa de medição dos hidrômetros. As vazões de referência e as pressões estabelecidas pelas condições hidráulicas foram controladas por registro de pressão RP-1, previamente calibrado, posicionado logo após o cavalete do hidrômetro de jusante $\left(\mathrm{H}_{2}\right)$. 
Duas situações distintas de funcionamento da rede de distribuição foram avaliadas: a primeira correspondente às condições normais de operação e, a outra, com abastecimento de água, após o esvaziamento total da rede. Essas condições são descritas a seguir.

\section{Condições normais de operação}

Para simular as condições normais de operação da rede de distribuição, em todos os testes, o sistema era cheio com água (sem bolsões de ar). Para tanto, após o acionamento do sistema de bombeamento, a válvula VE 4 ligada à ventosa era aberta, bem como os registros RG 1, RG 2 e RG 3, para permitir a recirculação da água pela tubulação de $100 \mathrm{~mm}$. Após a retirada do ar por meio da ventosa, a válvula VE 4 era fechada. Após esses preparativos para a retirada de ar da tubulação, iniciava-se o teste propriamente dito, acionando o variador de frequência da bomba e abrindo o registro RP 1, controlador da vazão, e a válvula VE-2. A determinação da eficiência dos equipamentos, em condições normais de operação da rede da bancada de testes, foi efetuada por meio das medidas dos volumes registrados nos hidrômetros $\mathrm{H}_{1}$ e $\mathrm{H}_{2}$, bem como o volume de água no reservatório calibrado, durante o intervalo de teste.

Para cada ensaio realizado, determinou-se a eficiência do equipamento, por meio da Equação 2, cujo numerador e denominador representam, respectivamente, o volume de ar retirado pelo equipamento testado e o volume de ar que penetra no ramal predial em condições normais de operação:

$\mathrm{E}=100[(\mathrm{~V} 1-\mathrm{V} 2) /(\mathrm{V} 1-\mathrm{Vr})]$

Equação 2

Sendo:

E : eficiência do equipamento (\%);

$\mathrm{V}_{1}$ : volume medido no hidrômetro $\mathrm{H}_{1}\left(\mathrm{~m}^{3}\right)$;

$\mathrm{V}_{2}$ : volume medido no hidrômetro $\mathrm{H}_{2}\left(\mathrm{~m}^{3}\right)$;

Vr: volume medido no reservatório calibrado $\left(\mathrm{m}^{3}\right)$.

\section{Condições de desabastecimento}

Para simular as condições de esvaziamento seguido de abastecimento da rede, inicialmente, toda a tubulação era preenchida com ar, cuja admissão efetuava-se por meio da ventosa. Em seguida, abriam-se a válvula VE 4 ligada à ventosa e a válvula VE 1 que efetuava o esvaziamento da rede e permitia o retorno da água ao reservatório principal. O sistema auxiliar de bombeamento era acionado para ajudar no esvaziamento da rede de distribuição e, quando utilizado, do recipiente de aferição. As válvulas VE 1 e VE 4 e o registro RG 1 eram posteriormente fechados. A seguir, acionava-se o sistema de bombeamento auxiliar, para agilizar no esvaziamento do reservatório calibrado. Após a admissão do ar através da ventosa, as válvulas VE 1 e VE 4 eram fechadas e o registro RG-1 aberto. Com a bomba principal ligada, o ar, empurrado pela água, escoava pelo ramal predial em teste.

A avaliação de eficiência do eliminador e do bloqueador de ar em situação de abastecimento, após o esvaziamento total da rede, realizava-se em duas etapas. Na primeira, avaliou-se, para cada uma das vazões em condições normais de abastecimento previamente estabelecidas, o volume de ar registrado no hidrômetro $\mathrm{H}_{2}$, sem válvula redutora de ar. O ensaio iniciava-se com o acionamento do variador de frequência previamente ajustado às condições de vazão e pressão pré-estabelecidas e com a abertura da válvula VE 2 durante 60 segundos. Esse tempo foi estabelecido após a constatação de que o mesmo garantiria somente a presença de ar na rede de abastecimento, válido somente para a pressão de $100 \mathrm{kPa}$. Na realização dos testes com a pressão de $500 \mathrm{kPa}$, reduziu-se o tempo para cada alteração na abertura do registro de pressão RP 1 .

Os ensaios para desabastecimento seguido de abastecimento sem os equipamentos eliminadores de ar foram efetuados para dois intervalos de tempo (180 e 300 segundos). Para os ensaios com tempo de 300 segundos e pressão de $500 \mathrm{kPa}$, somente foi possível verificar a quantidade de ar para as vazões de 0,18 e $0,50 \mathrm{~m}^{3} / \mathrm{h}$, uma vez que o reservatório calibrado ficou cheio antes de ser completado o tempo estabelecido para o ensaio.

$\mathrm{Na}$ segunda etapa, foi inserido o equipamento no cavalete de montante ou, no caso de bloqueador de ar, após o hidrômetro de jusante. Novamente determinou-se o volume de ar registrado no hidrômetro de jusante, para as mesmas condições hidráulicas e mesmo intervalo de tempo da primeira etapa (60 segundos) quando a pressão aferida foi de $100 \mathrm{kPa}$. Para os ensaios efetuados com a pressão de $500 \mathrm{kPa}$, o tempo foi reduzido de 60 segundos para a vazão de $0,18 \mathrm{~m}^{3} / \mathrm{h}$ até um mínimo de 10 segundos para a vazão de $1,50 \mathrm{~m}^{3} / \mathrm{h}$.

Para os testes da ventosa, foram adotados os mesmos procedimentos dos ensaios aplicados ao eliminador de ar e ao bloqueador de ar, sendo que a ventosa difere das demais por exigir a abertura simultânea das válvulas VE 2 e VE 4.

Dessa forma, a eficiência dos equipamentos destinados a minimizar o efeito do ar nas redes e nos ramais prediais em situação de abastecimento após esvaziamento da rede pôde ser determinada pela Equação 3.

$E=100 x\left(1-\frac{\left(V_{2}\right)_{\text {etapa } 2}}{\left(V_{2}\right)_{\text {etapa } 1}}\right)$ Equação 3

Sendo:

$\left(V_{2}\right)_{\text {etapa2 } 2}$ :volume medido no hidrômetro $\mathrm{H}_{2}$ com o eliminador de $\operatorname{ar}\left(\mathrm{m}^{3}\right)$;

$\left(V_{2}\right)_{\text {etapal }}$ :volume medido no hidrômetro $\mathrm{H}_{2}$ sem o eliminador de $\operatorname{ar}\left(\mathrm{m}^{3}\right)$. 
Tabela 1 - Resultados dos ensaios realizados em condição normal de operação da rede

\begin{tabular}{|c|c|c|c|c|c|c|}
\hline \multirow{2}{*}{ Vazão $\left(m^{3} / h\right)$} & \multirow{2}{*}{ Pressão (kPa) } & \multicolumn{5}{|c|}{ Volumes registrados $\left(\mathrm{m}^{3}\right)$} \\
\hline & & $\mathrm{V}_{1}\left(\mathrm{H}_{1}\right)$ & $\mathrm{V}_{2}\left(\mathrm{H}_{2}\right)$ & $\mathrm{V}_{\mathrm{R}}$ & $V_{1} / V_{R}$ & $\mathrm{~V}_{2} / \mathrm{V}_{\mathrm{R}}$ \\
\hline 0,59 & 100 & 0,02033 & 0,02038 & 0,01970 & 1,032 & 1,035 \\
\hline 0,83 & 100 & 0,02864 & 0,02879 & 0,02760 & 1,038 & 1,043 \\
\hline 1,22 & 100 & 0,03872 & 0,03859 & 0,03748 & 1,033 & 1,030 \\
\hline 1,33 & 100 & 0,03790 & 0,03787 & 0,03717 & 1,020 & 1,019 \\
\hline 1,37 & 100 & 0,03990 & 0,03984 & 0,03813 & 1,046 & 1,045 \\
\hline 1,47 & 100 & 0,03800 & 0,03845 & 0,03684 & 1,031 & 1,044 \\
\hline 0,17 & 500 & 0,00590 & 0,00557 & 0,00568 & 1,039 & 0,981 \\
\hline 0,32 & 500 & 0,01489 & 0,01477 & 0,01436 & 1,037 & 1,029 \\
\hline 0,57 & 500 & 0,01962 & 0,01913 & 0,01898 & 1,034 & 1,008 \\
\hline 1,05 & 500 & 0,03582 & 0,03535 & 0,03496 & 1,025 & 1,011 \\
\hline \multirow[t]{3}{*}{1,44} & 500 & 0,04946 & 0,04836 & 0,04797 & 1,031 & 1,008 \\
\hline & & & & Média & 1,033 & 1,023 \\
\hline & & & & jio padrão (\%) & 0,71 & 1,98 \\
\hline
\end{tabular}

Tabela 2 - Volumes de ar afluentes ao ramal predial para intervalo de 180 segundos

\begin{tabular}{|c|c|c|c|c|c|}
\hline \multirow{2}{*}{ Pressão(kPa) } & \multirow{2}{*}{$\begin{array}{l}\text { Vazão de referência } \\
\qquad\left(\mathrm{m}^{3} / \mathrm{h}\right)\end{array}$} & \multicolumn{3}{|c|}{ Volumes registrados $\left(\mathrm{m}^{3}\right)$} & \multirow{2}{*}{ Var/V2 (\%) } \\
\hline & & $\mathrm{V}_{2}=$ Var + água & VR & $\operatorname{Var}=\mathrm{V} 2-\mathrm{VR}$ & \\
\hline & 0,50 & 0,316 & 0,012 & 0,304 & 96,3 \\
\hline & 0,75 & 0,337 & 0,019 & 0,318 & 94,4 \\
\hline \multirow[t]{5}{*}{100} & 1,00 & 0,346 & 0,025 & 0,321 & 92,8 \\
\hline & 1,50 & 0,362 & 0,032 & 0,330 & 91,1 \\
\hline & 0,18 & 0,059 & 0,003 & 0,056 & 94,2 \\
\hline & 0,50 & 0,099 & 0,012 & 0,087 & 88,1 \\
\hline & 0,75 & 0,117 & 0,019 & 0,098 & 83,8 \\
\hline \multirow[t]{2}{*}{500} & 1,00 & 0,131 & 0,025 & 0,106 & 81,0 \\
\hline & 1,50 & 0,151 & 0,032 & 0,119 & 78,7 \\
\hline
\end{tabular}

\section{Resultados e discussão}

Realizaram-se três tipos de experimento. Os dois primeiros tiveram como objetivo principal verificar o teor de ar registrado pelo hidrômetro, inicialmente em condições normais de abastecimento de água e, posteriormente, quando o abastecimento ocorreu após total esvaziamento da tubulação. O terceiro experimento avaliou três tipos de equipamento destinados à retirada de ar.

\section{Quantificação de ar em condição normal de operação sem equipamento de eliminação}

Na Tabela 1 listam-se os valores de $\mathrm{V}_{1}$ (volume medido no hidrômetro $\mathrm{H}_{1}$ ), $\mathrm{V}_{2}$ (volume medido no hidrômetro $\mathrm{H}_{2}$ ) e $\mathrm{V}_{\mathrm{R}}$ (volume medido no reservatório calibrado), correspondendo à média de três ensaios realizados para as respectivas vazões afluentes e pressões. Nas duas últimas colunas, evidenciam que, nessas condições de operação, os volumes registrados nos hidrômetros (V1 e V2) 
Tabela 3 - Volumes de ar afluentes ao ramal predial para intervalo de 300 segundos

\begin{tabular}{lcccc}
$\begin{array}{l}\text { Vazão de } \\
\text { referência } \\
\left(\mathrm{m}^{3} / \mathrm{h}\right)\end{array}$ & \multicolumn{3}{c}{ Volumes registrados $\left(\mathrm{m}^{3}\right)$} & \\
\cline { 2 - 4 } & $\mathrm{V}_{2}=$ Var+água & VR & Var=V2-VR & \\
\hline 0,18 & 0,048 & 0,003 & 0,045 & 92,9 \\
\hline 0,50 & 0,348 & 0,036 & 0,312 & 89,6 \\
\hline 0,75 & 0,377 & 0,051 & 0,326 & 86,4 \\
\hline 1,00 & 0,391 & 0,064 & 0,327 & 83,6 \\
\hline 1,50 & 0,409 & 0,081 & 0,328 & 80,1 \\
\hline
\end{tabular}

e no reservatório de calibração (VR) são praticamente iguais, assertiva corroborada pelo baixo desvio-padrão. As diferenças entre esses valores são inferiores aos erros normalmente verificados para essa classe $(C)$ de hidrômetros. Como os valores de $V_{R}$ correspondem ao volume de água nas condições normais de temperatura e pressão, na qual a concentração de ar é insignificante (da ordem de $2 \%$ em volume), pode-se concluir que, nessas condições, os valores de $\mathrm{V}_{1}$ e $\mathrm{V}_{2}$ correspondem tão somente ao volume de água afluente. Ressalta-se ainda que a perda de carga no ramal predial, superior à carga piezométrica estabelecida de $10 \mathrm{mca}$, impossibilitou vazões superiores a $1,47 \mathrm{~m}^{3} / \mathrm{h}$ para pressão de $100 \mathrm{kPa}$.

\section{Quantificação do ar em condição atípica de operação sem equipamento de eliminação}

Para verificar a influência da descontinuidade do abastecimento na presença do ar numa ligação predial, foram efetuados ensaios de esvaziamento total da rede seguidos de abastecimento, com intervalos de tempo de 180 e 300 segundos. Para o tempo de 180 segundos, na Tabela 2 apresentam-se os volumes de água medidos no hidrômetro $\left(V_{2}\right)$ que efetivamente afluem ao reservatório de calibração. Para pressão de $100 \mathrm{kPa}$, foram ensaiadas vazões de 0,50 a $1,50 \mathrm{~m}^{3} / \mathrm{h}$, uma vez que, para $0,18 \mathrm{~m}^{3} / \mathrm{h}$, o tempo de 180 segundos mostrou-se insuficiente para que o sistema entrasse em carga.

A primeira constatação de que os resultados da Tabela 2 suscitam refere-se à igualdade dos volumes afluentes ao reservatório de calibração para os valores extremos de pressão de 100 e $500 \mathrm{kPa}$, numa mesma vazão. Depreende-se também que os significativos volumes de ar afluentes ao ramal predial - como a $6^{a}$ coluna da Tabela 2 denota - reduziram-se com o aumento da pressão, parecendo tornar menos suscetíveis à afluência de ar as ligações localizadas em pontos sujeitos a pressões mais elevadas das redes de distribuição de água. Como seria de se esperar, tal redução obedeceu a lei de BoyleMariotte $\left(\mathrm{P}_{1} \mathrm{~V}_{1}=\mathrm{P}_{2} \mathrm{~V}_{2}\right)$, pois houve aumento de aproximadamente

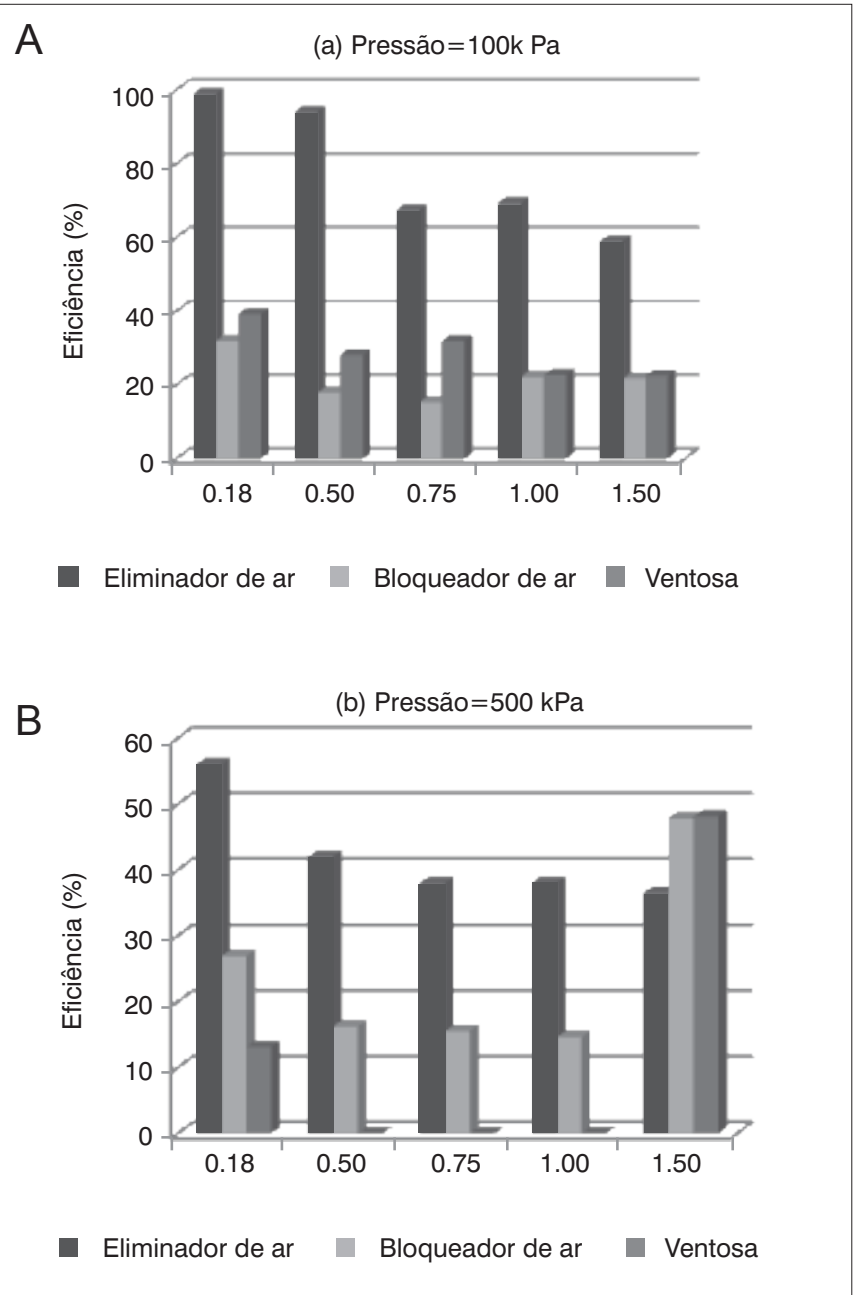

Figura 5 - Eficiência média na remoção de ar dos equipamentos em função da pressão.

200\% na pressão absoluta (de $192 \mathrm{kPa}$ para $592 \mathrm{kPa}$ ) e os volumes de ar reduziram-se de mesma ordem de grandeza.

Para o intervalo de tempo entre desabastecimento e abastecimento de 300 segundos, não foi possível realizar ensaios à pressão de $500 \mathrm{kPa}$, pois o reservatório de calibração não apresentava volume necessário para receber o caudal aduzido pela bomba durante esse período. Dessa forma, na Tabela 3 listam-se os resultados obtidos para pressão de $100 \mathrm{kPa}$.

Da análise dos resultados da Tabela 3 verificou-se a mesma tendência de aumento relativo do volume de ar afluente, pois os volumes de água variaram de 7,1 a 19,9\% do registrado pelo hidrômetro para as vazões de 0,18 a $1,50 \mathrm{~m}^{3} / \mathrm{h}$. Todavia, a despeito da mesma magnitude dos volumes de água obtidos para o tempo de 180 segundos (5,8 a 21,3\%), vale ressaltar que houve redução do volume de ar afluente para as quatro vazões de referência. Como houve aumento do intervalo de tempo de 180 para 300 segundos, o volume de água aduzido ao recipiente calibrado aumentou, mas o volume de ar permaneceu praticamente o mesmo, em torno de $0,32 \mathrm{~m}^{3}$ para vazões 
superiores a $0,50 \mathrm{~m}^{3} / \mathrm{h}$. Esse volume corresponde à capacidade de armazenamento no interior da tubulação à pressão de $100 \mathrm{kPa}$. Dessa forma, é possível afirmar - na realidade, confirmar -, que, quanto maior a duração da paralisação do abastecimento e o comprimento do setor da rede de distribuição, maior será a afluência de ar aos ramais domiciliares.

\section{Avaliação dos equipamentos eliminadores de ar}

Para a situação de desabastecimento, conforme ressaltado na Metodologia, avaliaram-se dois eliminadores e dois bloqueadores de ar (de mesmo fabricante), e uma ventosa, com o cálculo da eficiência do equipamento realizado por meio da Equação 2. Vale mencionar que cada resultado de eficiência do equipamento refere-se à média de cinco ensaios para cada pressão na rede de distribuição (100 e 500 kPa).

Os resultados do eliminador de ar apontaram significativa eficiência, atingindo $98,9 \%$ para vazão de $0,18 \mathrm{~m}^{3} / \mathrm{h}$ e pressão de $100 \mathrm{kPa}$. Mantida essa pressão, à medida que a vazão se elevava, a eficiência do equipamento reduzia-se, atingindo 59\% para $1,50 \mathrm{~m}^{3} / \mathrm{h}$. O aumento da pressão da rede para $500 \mathrm{kPa}$ resultou em significativa redução da eficiência do equipamento (de 36,5 a 56\%). Novamente a eficiência reduziu-se com o aumento da vazão afluente ao ramal.

Para ensaios nas mesmas circunstâncias, o bloqueador de ar apresentou eficiência significativamente inferior e em uma única condição de ensaio - pressão $500 \mathrm{kPa}$ e vazão $1,50 \mathrm{~m}^{3} / \mathrm{h}$, eficiência de 47,8\%. A tendência de redução de desempenho com o aumento da pressão e da vazão mostrou-se menos pronunciada. Após esse resultado atípico, essa condição de ensaio foi repetida diversas vezes com eficiência, mantendo-se na mesma magnitude. Vale também salientar que, para ambas as pressões, verificaram-se baixos coeficientes de variação, cujo valor máximo atingiu 2,99\% para um dos ensaios realizados à pressão $100 \mathrm{kPa}$. Esse parâmetro variou de 0,98 a 1,80\% para os ensaios à pressão $500 \mathrm{kPa}$.

Por fim, segundo as mesmas condições hidráulicas estabelecidas para os outros dois equipamentos, realizaram-se ensaios com uma ventosa instalada do final da tubulação de $100 \mathrm{~mm}$ a montante do ramal predial. Para pressão de $100 \mathrm{kPa}$, a ventosa apresentou a menor eficiência dentre os equipamentos testados (sem, contudo, exibir tendência de redução de desempenho com o aumento de vazão), ainda que para as vazões de 1,00 e $1,50 \mathrm{~m}^{3} / \mathrm{h}$ desempenho praticamente igual aos bloqueadores de ar.

$\mathrm{Na}$ Figura 5A apresentam-se as médias das eficiências de cada equipamento para os ensaios realizados à pressão de $100 \mathrm{kPa}$, na qual se evidencia o melhor desempenho dos eliminadores de ar. Nos ensaios realizados à pressão de $500 \mathrm{kPa}$, a ventosa apresentou desempenho inconsistente, com valores nulos de remoção de ar para as três vazões intermediárias ensaiadas e o melhor desempenho registrado para $1,50 \mathrm{~m}^{3} / \mathrm{h}$ (Figura 5B). A eficiência nula pareceu se dever a uma provável aderência do flutuador ao anel de vedação do orifício de saída de ar durante a realização dos ensaios. Para vazão máxima, atribui-se esse aumento da eficiência às características de projeto do equipamento, que opera melhor quando as velocidades de escoamento do fluido bifásico e as pressões são mais significativas, a exemplo do que ocorreu com o bloqueador de ar.

\section{Conclusões e recomendações}

A partir dos resultados dos diversos ensaios realizados, nas condições normais e atípicas de operação da rede de distribuição, é possível tecer as seguintes conclusões:

- em condição normal de operação do sistema de abastecimento, a concentração de ar afluente aos ramais prediais é desprezível e não justifica instalação de qualquer equipamento destinado ao bloqueio ou à eliminação de ar;

- como esperado, os hidrômetros velocimétricos comumente utilizados para medição domiciliar apresentam erros sistemáticos ao aferir o volume do escoamento bifásico ar-água;

- em vertente semelhante, confirmou-se que a magnitude da afluência de ar aos ramais prediais é diretamente proporcional ao tempo de desabastecimento e ao comprimento do setor da rede de distribuição ao qual o domicílio se conecta;

- dos três equipamentos avaliados, o eliminador de ar apresentou melhor desempenho para ambas pressões avaliadas (100 e $500 \mathrm{kPa}$ ). Esse desempenho tendeu a se reduzir com o aumento da vazão afluente e da pressão. Todavia, vale novamente ressaltar que a ausência de normatização, quanto às especificações técnicas, para tais equipamentos, não permite a generalização desses resultados;

- aliado à baixa eficiência, o emprego do bloqueador de ar não é recomendado pela perspectiva de sobremedição nas ligações circunvizinhas, pois o bloqueio do ar transportado pode contribuir para que os bolsões de ar contidos no ramal predial retornem à rede de abastecimento, influenciando na medição do hidrômetro mais próximo;

- a menor vazão afluente associou-se ao maior volume de ar aferido pelo hidrômetro. Dessa forma, é possível supor que os consumidores situados na menor faixa de consumo (usualmente relacionados às menores faixas de renda) sejam os mais prejudicados pela situação de desabastecimento. Essa constatação justifica ainda mais a mencionada redução do volume mínimo tarifado praticado por diversos prestadores de serviços de abastecimento de água do País.

\section{Agradecimentos}

Os autores agradecem à Fapemig no contexto do Programa Pesquisador Mineiro:Proc.4754-6. 


\section{Referências}

FALVEY, H.T. Air-water flow in hydraulic systems. United States Bureau of Reclamation. Engineering Monograph n. 41, 1980.

LEAL, F.C.T.; TEIXEIRA, J.C. O ar nas contas de água, Revista de Engenharia Sanitária e Ambiental, v. 6, n. 3, p. 96-97, 2004.

LITTLE, M.J. Air transport in water and effluent pipelines. In: 2nd INTERNACIONAL CONFERENCE ON MARINE WASTE DISCHARGES, Istanbul, p.16-20, 2002.
MELLO, E.J.; FARIAS, R.L. O ar e sua influência na medição do consumo de água. In: ANAIS ELETRÔNICOS DO $21^{\circ}$ CONGRESSO BRASILEIRO DE ENGENHARIA SANITÁRIA E AMBIENTAL, CD-ROM, ABES, João Pessoa, 2001

RECH, A.L. Água: micromedição e perdas. 2. ed. São Paulo: Scortecci, 1999.

TSUTIYA, M.T. Abastecimento de água. 2. ed. São Paulo: Departamento de Engenharia Hidráulica e Sanitária da Escola Politécnica da Universidade de São Paulo, 2005. p. 156-192. 